\title{
24-HYDROXYGLYCYRRHETIC ACID FROM THE ROOTS \\ OF Glycyrrhiza korshinskyi
}

\author{
N. P. Kir'yalov, V. F. Bogatkina,
}

UDC 547.913 and T. P. Nadezhina

We have hydrolyzed a mixture of unpurified saponins $(84 \mathrm{~g})$ obtained by the acidification of a concentrated sodium carbonate and aqueous extract of the roots and rhizomes of Glycyrrhiza korshinskyi G. Grig. by heating it with $6 \%$ methylsulfuric acid in the water bath for $17 \mathrm{~h}$.

The neutral hydrolysis products $(23.5 \mathrm{~g})$ were separated on inactive alumina $(1: 100)$. The first fractions, eluted with a mixture of petroleum ether and diethyl ether $(1: 1)$, contained a mixture of homo- and heteroannular dienes (0.1-0.2\%). Then the main hydrolysis product (about $50 \%$ ) - methyl glycyrrhetate, identified by its UV and IR spectra - was eluted. After the removal of the methyl glycyrrhetate, fractions were obtained consisting of mixtures of homo- and heteroannular dienes $(0.2 \%)$. One of the substances of these fractions was the methyl ester of a triterpene acid, $\mathrm{C}_{31} \mathrm{H}_{48} \mathrm{O}_{4}, \operatorname{mp~} 264^{\circ} \mathrm{C}, \mathrm{M}^{+} 484$, UV spectrum: $\lambda_{\max }$ $280 \mathrm{~nm}$; IR spectrum: $1730,3200-3300 \mathrm{~cm}^{-1}$.

From the following fractions, eluted with a mixture of diethyl ether and chloroform ( $1: 3$ ), we isolated a substance (6\%) with the formula $\mathrm{C}_{31} \mathrm{H}_{48} \mathrm{O}_{5}, \mathrm{mp} 245-246^{\circ} \mathrm{C}, \mathrm{M}^{+} 500$; UV spectrum: $\lambda_{\max } 248 \mathrm{~nm}$; IR spectrum: $1620,1660,1727,3200-3500 \mathrm{~cm}^{-1}$. Its acetylation with a mixture of pyridine and acetic anhydride formed a diacetate, $\mathrm{C}_{35} \mathrm{H}_{52} \mathrm{O}_{7}, \mathrm{mp} 256-257^{\circ} \mathrm{C}, \mathrm{M}^{+} 584 ; \mathrm{UV}$ spectrum: $\lambda_{\max } 248 \mathrm{~nm}$; IR spectrum: 1620 , $1660,1735 \mathrm{~cm}^{-1}$.

The triterpene acid methyl ester with $\mathrm{mp} 245-246^{\circ} \mathrm{C}$ that was obtained is identical in properties and spectra with the methyl 24-hydroxyglycyrrhetate isolated previously from the roots of Glycyrrhiza glabra L. by Italian workers [1].

The hypogeal organs of Glycyrrhiza korshinskyi were collected by T. P. Nadezhina on June 5, 1970, in the flowering phase in the Kazakh SSR (environs of Chelkar station).

\section{LITERATURE CITED}

1. L. Canonica, B. Danieli, P. Mannito, G. Russo, and A. Bonati, Gazz. Chim. Ital., 97 (10), 1359 (1967).

V. L. Komarov Botanic Institute, Academy of Sciences of the USSR. Translated from Khimiya Prirodnykh Soedinenii, No. 3, pp. 395-396, May-June, 1972. Original article submitted January $17,1972$.

- 1974 Consultants Bureau, a division of Plenum Publishing Corporation, 227 W'est 17th Street, New York, N. Y. 10011. No part of this publication may be reproduced, stored in a retrieval system, or transmitted, in any form or by any means, electronic, mechanical, photocopying, microfilming, recording or otherwise, without written permission of the publisher. A copy of this article is available from the publisher for $\$ 15.00$. 